\title{
ECHO INTEGRATION NEAR THE SEABED
}

\section{Masahiko Furusawa}

Tokyo University of Marine Science and Technology, Tokyo, Japan., frsw@fine.ocn.ne.jp

Follow this and additional works at: https://jmstt.ntou.edu.tw/journal

Part of the Aquaculture and Fisheries Commons

\section{Recommended Citation}

Furusawa, Masahiko (2011) "ECHO INTEGRATION NEAR THE SEABED," Journal of Marine Science and Technology.

Vol. 19: Iss. 3, Article 4.

DOI: $10.51400 / 2709-6998.2190$

Available at: https://jmstt.ntou.edu.tw/journal/vol19/iss3/4

This Research Article is brought to you for free and open access by Journal of Marine Science and Technology. It has been accepted for inclusion in Journal of Marine Science and Technology by an authorized editor of Journal of Marine Science and Technology. 


\title{
ECHO INTEGRATION NEAR THE SEABED
}

\author{
Masahiko Furusawa*
}

Key words: echo integration, seabed echo, dead zone.

\begin{abstract}
The echo integration (EI) method has long been used for fish abundance estimations. The method is applicable to any type of fish distribution and the analysis is easy to perform by advanced software. For fish near the seabed, however, sometimes it is difficult to perform an analysis because of so-called dead zones. In this paper, the EI near the seabed is considered, reviewing past studies and introducing some new ideas such as an unsampled zone. For the consideration, close inspection of the EI theory is necessary and a section is devoted to the purpose. As an application of the EI near the seabed, a combined measurement of the volume backscattering strength of demersal fish and the surface scattering strength of the seabed is demonstrated.
\end{abstract}

\section{INTRODUCTION}

The echo integration (EI) method has long been used to estimate fish abundance [22]. The EI method is robust, because it is applicable to any distribution pattern of fish, schooling, dispersed, or layered, and is easy to be implemented by up-to-date computer programs.

The EI for fish near the seabed, however, is not necessarily easy because of the interference from strong seabed echoes. Such zone is called the dead zone (also called blind zone or shadow zone) near the seabed, and has long been discussed and some countermeasures have been proposed [13, 16, 18, 19]. But, the dead zone is not so severe as has been stressed, and more insight will be necessary for true understanding of the zone: for example, sometimes an unsampled zone, which could be measured, is confused with the dead zone. The main purpose of this paper is to show methods or caution to conduct effective and accurate EI near the seabed.

For the understanding of the dead zones near the seabed, a review of the theory of the EI is necessary and the next section is devoted to it. As an application of the EI near the seabed, combined measurements of the volume backscattering strength of bottom fish and the surface scattering strength of seabed are

Paper submitted 05/03/10; revised 06/03/10; accepted 06/11/10. Author for correspondence: Masahiko Furusawa (e-mail:frsw@fine.ocn.ne.jp).

*Tokyo University of Marine Science and Technology, Tokyo, Japan. demonstrated in the last section.

\section{ECHO INTEGRATION METHOD: A REVIEW}

Looking back to the history of the fisheries acoustics, an echo integrator was first developed for echo counting of individual echoes $[4,23]$. Instead of directly counting echo pulses as $1,2,3, \ldots$, the integration of the echo pulses gave a total area which is proportional to the number of echo pulses. In this method, the integrand was the echo amplitude. Fish distribution density is proportional to the echo amplitude squared [17, $21,25]$, and later echo integrators have integrated the squared amplitudes. The earlier echo integrators were analogue echo integrators which used analogue circuits.

Range dependence-compensated echo-envelope ( $E, \mathrm{TVG}$ output) squared is proportional to the volume backscattering strength ( $\mathrm{SV}$, variable $S_{V}$ ) which is the product of distribution density $(n)$ and the linear value of average target strength (TS) of fish (variable $T_{S}$ ):

$$
E^{2}=k S_{V}=k n T_{S}
$$

where $k$ is a constant including the source pressure, sensitivities, and gains. The linear value of the TS is defined in Ref. [20] as

$$
T_{S}=I_{r} / I_{i}
$$

where $I_{i}$ is the incident intensity and $I_{r}$ is the reflected intensity transformed at $1 \mathrm{~m}$ from a target. The relation between decibel TS (variable TS) and backscattering cross section $\sigma_{b s}$ is

$$
T S=10 \log T_{S}=10 \log \left(\sigma_{b s} / r_{0}^{2}\right)
$$

where $r_{0}$ is the reference range $(1 \mathrm{~m})$.

From the limitation of electronic technique, the analogue integrator first performs integration of $E^{2}$ over range $r$ (or time from the transmission of the pulse) and second over pings to get average SV:

$$
<S_{V}>=\frac{1}{k} \frac{1}{J} \sum_{j=1}^{J}\left(\frac{1}{r_{w}} \int_{r}^{r+r_{w}} E^{2} d r\right)
$$

where $r$ to $r+r_{w}$ is the range gate as an integration layer, $j$ is 


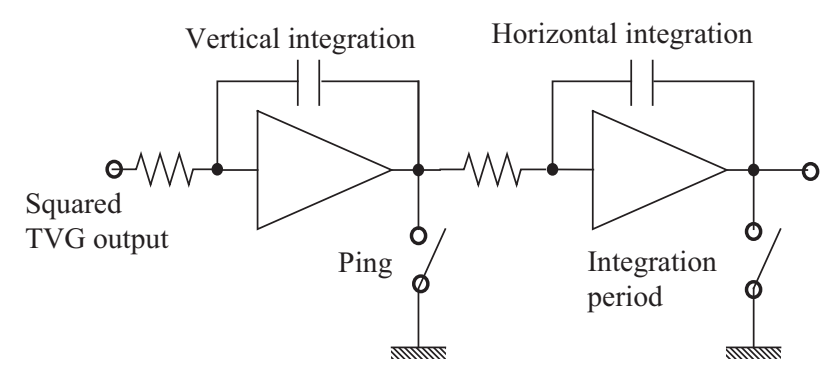

Fig. 1. Principle of the analogue echo integrator.

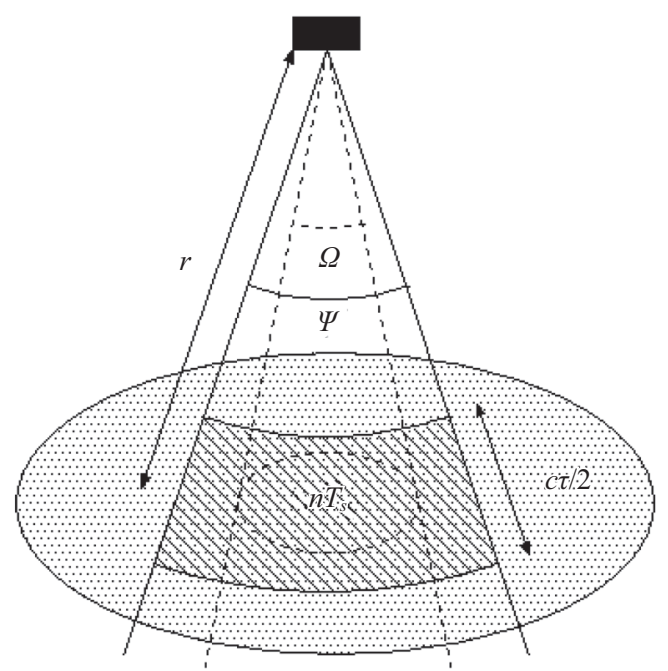

Fig. 2. Geometry of the volume backscattering. Solid lines are for the case of a large school comparing with beam spread and dotted lines for a small school.

the index of ping and $J$ corresponds to the integration period, and $\langle\ldots>$ indicates averaging or integration processing. Then we have the average SV for each integration cell $\left(r_{w} \times J\right)$. Fig. 1 shows the principle of the analogue echo integrator. The first integration or vertical integration was made for echoes in each ping and the second or horizontal integration was made for the output of the 1st integration for each integration period.

The theoretical foundation of Eq. (1) is the volume backscattering or reverberation theory $[5,20,26]$ which gives the relationship between the echo pressure amplitude $P$ and $\mathrm{SV}$ (see Fig. 2):

$$
\begin{gathered}
P^{2}=P_{0}^{2} \frac{1}{r^{2} 10^{0.2 \alpha r}} \frac{c \tau}{2} \Psi S_{V} \\
\Psi=\int_{4 \pi} D^{4}(\theta) d \Omega
\end{gathered}
$$

where $P_{0}$ is the source pressure amplitude, $\alpha$ is the absorption coefficient, $c$ is the sound speed, $\tau$ is the pulse width, $\Psi$ is the equivalent beam angle, $D$ is the pressure directivity function, $\theta$ is polar angle measured from the beam axis, and $\Omega$ is the solid angle. This theory has been confirmed by an experiment using

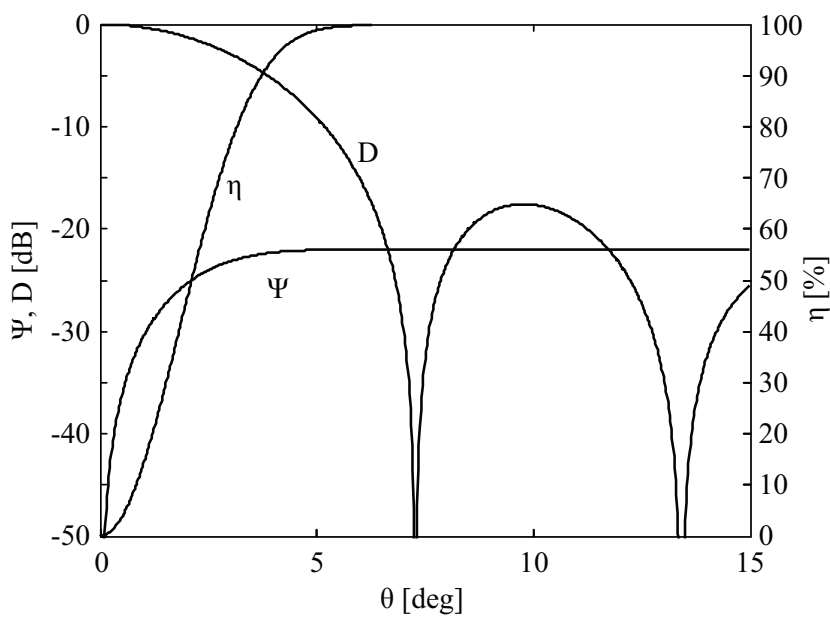

Fig. 3. Directivity $(D)$, equivalent beam angle $(\Psi)$, and contribution factor $(\eta)$ for $38 \mathrm{kHz}$ and $28 \mathrm{~cm}$-diameter transducer as a function of angle $(\theta)$.

tennis balls in air [21], by a rigorous experiment using actual fish in cage [6], and by a computer simulation [7].

If fish distribution is sufficiently broader than the beam spread and homogeneous, the equivalent beam angle becomes a constant value, because the integration can be made for the whole solid angle of $4 \pi$ as shown in Eq. (6). But, if a fish distribution is smaller than the beam spread, the equivalent beam angle must be a function of distribution angle $\Omega$ as shown in Fig. 2:

$$
\Psi(\Omega)=\int_{\Omega} D^{4}(\theta) d \Omega
$$

This makes the general application of the volume backscattering theory difficult. How is it possible to find the application limit of the volume backscattering theory? To answer the question, a contribution factor $\eta$ defined as the ratio of the two equivalent beam angles is introduced $[8,9]$ :

$$
\eta=\frac{\Psi(\Omega)}{\Psi(4 \pi)} \times 100 \quad[\%] .
$$

Fig. 3 indicates an example of the directivity, the equivalent beam angle, and the contribution factor for a $38 \mathrm{kHz}$ and 28 $\mathrm{cm}$-diameter transducer as a function of the polar angle $\theta$ which is related to $\Omega$ by

$$
\Omega=2 \pi(1-\cos \theta)
$$

The equivalent beam angle reaches an asymptotic value of $\Psi(4 \pi)$ where the contribution factor reaches $100 \%$. At the directivity of $-3 \mathrm{~dB}(-3 \mathrm{~dB}$-beam-angle), $\eta$ is approximately $80 \%$, and at $-6 \mathrm{~dB}$-beam-angle, $\eta$ is $95 \%$. The angle where $\eta$ is $\mathrm{x} \%$ is called " $\mathrm{x} \%$-beam-angle." Generally, the $95 \%$-beamangle is approximately $-6 \mathrm{~dB}$-beam-angle and 1.4 times $-3 \mathrm{~dB}$ beam-angle: 


$$
\theta_{95 \%} \cong \theta_{-6 d B} \cong 1.4 \theta_{-3 d B} .
$$

To discuss an effective angle range of the volume backscattering, it is better to use this $95 \%$-beam-angle. If a fish school size relative to the beam spread measured by the $95 \%$ beam-angle is smaller than unity, the estimated volume backscattering strength by Eqs. (5) and (6) has a negative bias. This fact should be considered when the packing density of individual school is main concern $[3,10]$.

Differing from the analogue echo integrator, thanks to highly developed digital technology, currently the integration or averaging is firstly made for pings and secondly for range as

$$
<S_{V}>=\frac{1}{r_{w}} \int_{r}^{r+r_{w}}\left(\frac{1}{J} \sum_{j=1}^{J} S_{V}\right) d r .
$$

The result of averaging is called the average SV and the original non-averaged value, $S_{V}$ of Eq. (5), is called the raw SV.

The EI is an extension of the volume backscattering theory for complicated fish distributions including single fish, small schools, and even space, not only large schools. The extension becomes possible by the averaging process in Eq. (11) over pings and range; especially the ensemble averaging is essential for the EI. By the averaging, it becomes possible to assume that a very large and homogeneously distributed fish school might be observed, and then the constant equivalent beam angle $\Psi(4 \pi)$ can be used.

Here, the essence of the EI method is listed:

1) The EI method is the extension of the volume backscattering theory to match to complex distribution of fish;

2) The EI relaxes limitation of the volume backscattering theory, that is, fish distribution must be homogeneous and larger than the beam spread;

3) Historically, the vertical integration was conducted first, but, in principle, the horizontal averaging is essential and is better to be done first;

4) Up-to-date digital and computer technology has enabled this order of integration, and enabled ensemble averaging over pings for each high-speed sampled data; and

5) In the EI or volume scattering, the \%-beam-angle is more appropriate, than the beam width to describe an effective beam range.

\section{DEAD ZONE NEAR THE SEABED}

\section{Definitions of Dead Zones by Ona and Mitson}

Ona and Mitson defined the integrator dead zone which is comprised of three dead zones as shown in Fig. 4 [18]. The acoustic dead zone (ADZ) is the zone where weak fish echoes are buried in a strong seabed echo. The backstep zone (BSZ) is a manually set zone to eliminate a chance to include seabed echoes in integration. The partial integration zone (PIZ) is

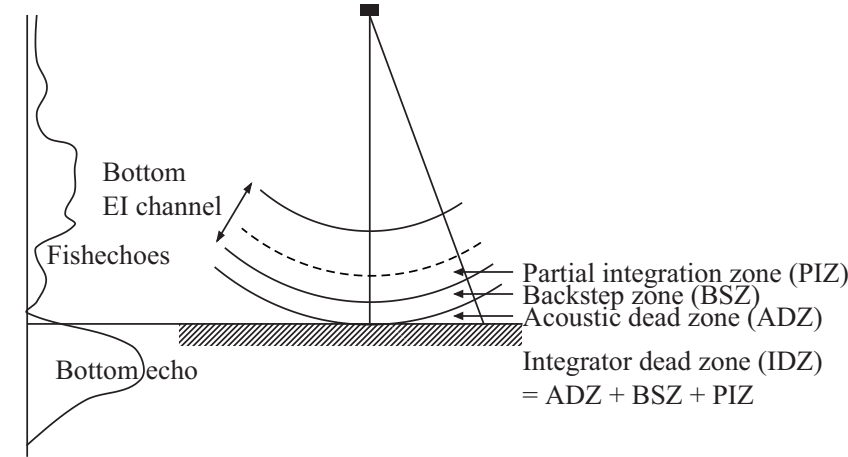

Fig. 4. Integrator dead zone defined by Ona and Mitson [18].

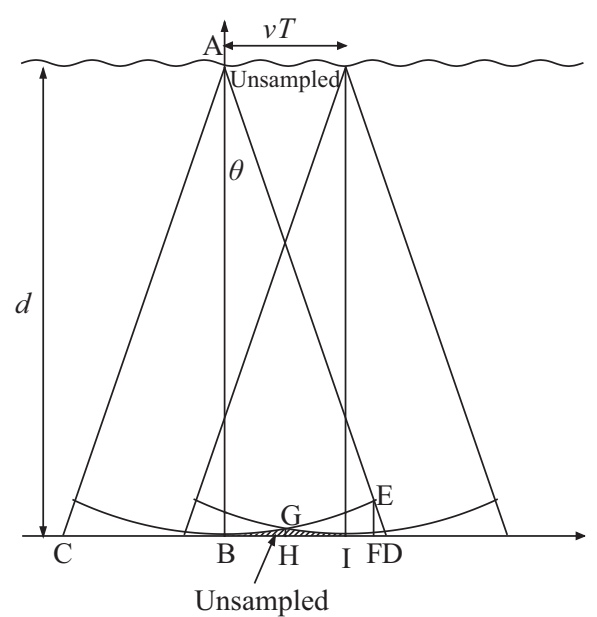

Fig. 5. Unsampled zones appeared between neighboring two beams.

defined as the zone where fish echoes are not completely integrated. The sum of these three dead zones is called the integrator dead zone (IDZ). These zones are examined below.

\section{Acoustic Dead Zone}

Fig. 5 shows two adjacent beams emitted from a moving vessel. As can be seen easily, a part of the ADZ of the first beam, GEDIG, is mostly sampled by the second beam and is not a dead zone. Certainly the zone BGIB is unsampled, but can be sampled by slowing the vessel, or the zone is interpolated by neighboring sampled zones. In that sense, this bottom unsampled zone is similar to the surface unsampled zone as shown in the figure.

From a simple geometry, the coordinates $(\mathrm{BH}, \mathrm{GH})$ and $(\mathrm{BF}$, EF) are derived as

$$
\begin{gathered}
(\mathrm{BH}, \mathrm{GH})=\left(\frac{v T}{2}, \frac{v^{2} T^{2}}{8 d}\right) \\
T=K \frac{2 d}{c}
\end{gathered}
$$

$$
(\mathrm{BF}, \mathrm{EF})=\left[d \sin \theta_{95 \%}, d\left(1-\cos \theta_{95 \%}\right)\right]
$$




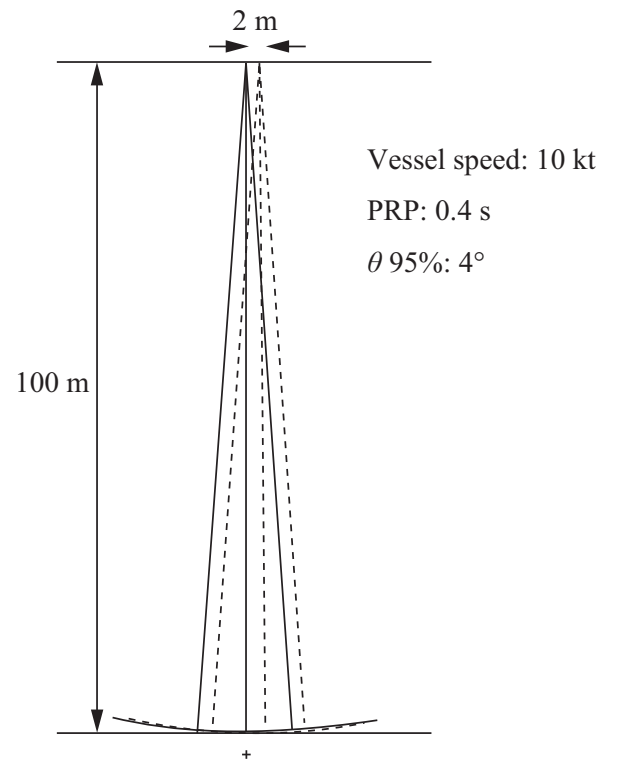

Fig. 6. Neighboring two beams for actual sounding parameters. The bottom unsampled zone is very small and could not be seen.

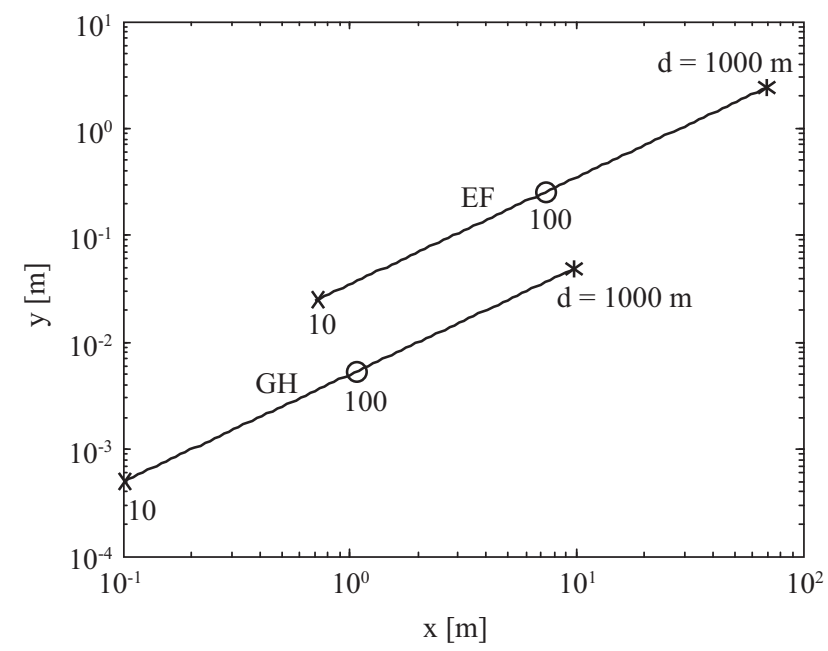

Fig. 7. The $x$ and $y$ coordinates (origin at B) of $\mathrm{E}$ and $\mathrm{G}$ shown in Fig. 5 . Parameter $d$ is bottom depth.

where $v$ is the vessel speed, $T$ is the pulse repetition period (PRP), $K$ is a constant around 3, and $d$ is the bottom depth. EF is not the height of the dead zone, but important, because the echoes of fish near $\mathrm{E}$ are merged with the echoes near B. Note that the GH is determined by vessel speed, and EF by the 95\%-beam-angle.

Fig. 6 shows a similar figure to actual conditions of $v=10$ $\mathrm{kt}, T=0.4 \mathrm{~s}, d=100 \mathrm{~m}$, and $\theta_{95 \%}=4^{\circ}$; the vessel moves $2 \mathrm{~m}$ in one PRP. As can be seen, the unsampled zone is actually indistinguishable and the height EF is very small for the ordinary survey parameters.

Fig. 7 demonstrates the calculated $x-y$ coordinates of $\mathrm{G}$ and $\mathrm{E}$ with the origin at B for the typical value of $K=3$ and $v=10 \mathrm{kt}$. For a depth of $d=100 \mathrm{~m}$, GH is only $5 \mathrm{~mm}$ and EF is $25 \mathrm{~cm}$.

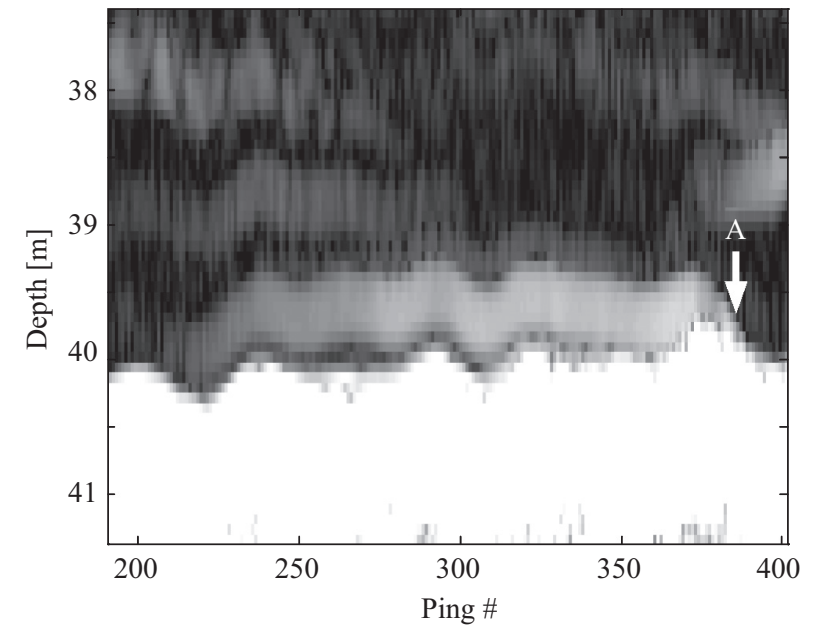

Fig. 8. Echogram showing the echotrace of a fish which was touching the seabed around $A$.
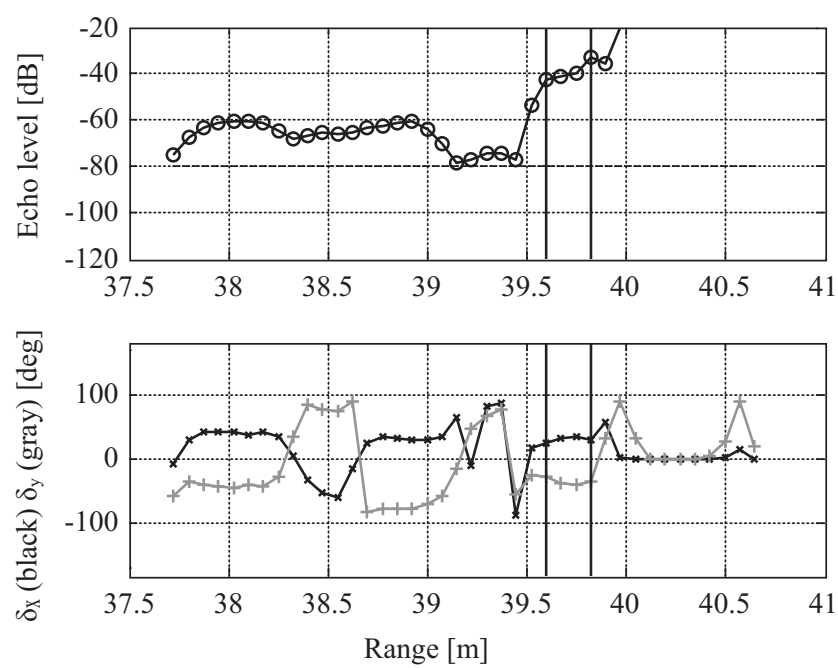

Fig. 9. The echo level (upper) and split-beam phase differences (lower) for the bottom touching fish shown in Fig. 8. Markers indicate sampled points. Flat parts gated by vertical bold lines show the fish echo.

From the discussion above, there is no ADZ and the bottom usampled zone is negligible.

\section{Backstep Zone}

The echogram in Fig. 8 shows an example echo-trace from a fish which touched the seabed around A. Even after the touching, flat parts of echo envelope and split-beam phase differences are obtained as shown in Fig. 9. Apparently the end part of the fish echo is buried in the bottom echo, but the amplitudes at the frontal part of the echo can be measured. As mentioned above, recent echo integrators first sample echo envelope at a high sampling frequency such as $10 \mathrm{kHz}(100 \mu \mathrm{s}$ in period, $7.5 \mathrm{~cm}$ in range), so that the echo amplitude or power is measurable even for this type of fish echo. Therefore, ideally, fish touching with seabed is measurable. 


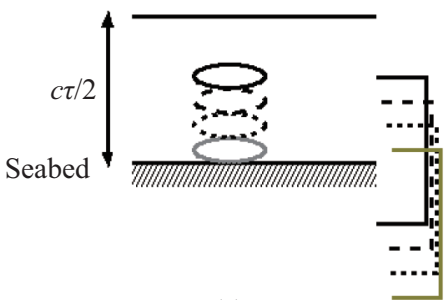

(a)

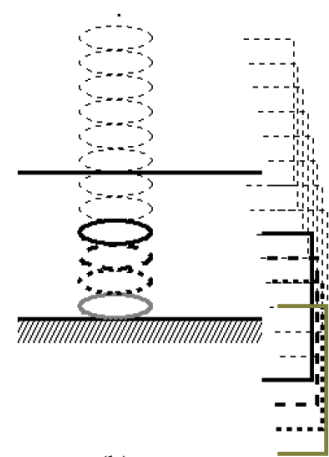

(b)
Fig. 10. Underestimation occurs for a thin fish layer just above the seabed (a), but if there is another similar layer above it (b), echo energy is introduced and underestimation does not occur.

Next, consider the case of a thin fish layer just above the seabed as shown by a simplified sketch in Fig. 10(a). An ellipse indicates a fish and the echo pulse is simplified as a rectangular shape. If fish distribution is thin, considerable part of echo energy is buried in the seabed echo. Therefore, if an integration layer includes the layer with thickness $c \tau / 2$ just above the seabed, the integration result becomes too small. Therefore, this layer just above the seabed is a partial integration layer. But, this is not always true. If there are other fish above the former fish as shown in Fig. 10(b), the echo energy is introduced to the layer and the estimated result will be reasonable.

Other than this problem, there are some other factors to make reasonable integration difficult just above the seabed. Local bottom sloping and roughness in the scale of the beam spread, inevitable rise time of echo pulse, and variability in bottom detection are those factors. Therefore, some backstep (or offset), for example $\Delta r=c \tau / 4$, is necessary. This causes a dead zone and if there are fish in the zone, some correction is necessary.

Fig. 11 shows an example of a correction method for the BSZ. The area backscattering strength (SA) including the BSZ is corrected by the SV just above the BSZ by

$$
S_{A}{ }^{\prime}=S_{A}+\Delta r S_{V}
$$

where $S_{A}$ is $\mathrm{SA}$ value above the BSZ, $\Delta r$ is the thickness of the BSZ, and $S_{V}$ is $\mathrm{SV}$ value just above the BSZ. Correction methods depend on fish distribution and scrutiny of echogram is important.

\section{Partial Integration Zone}

The last dead zone which Ona and Mitson proposed is the PIZ. The discussion for this dead zone is similar to BSZ and one can easily understand Fig. 12. The bottom EI channel is to be considered. As before, underestimation occurs for lower part of this channel, but if homogeneous and large distribution of fish is assumed, an overestimation part also exists for this

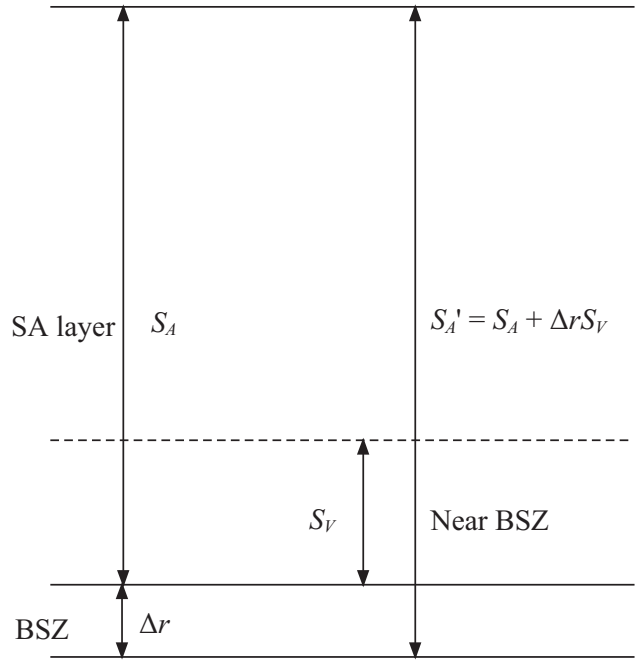

Fig. 11. A correction method for the backstep zone.

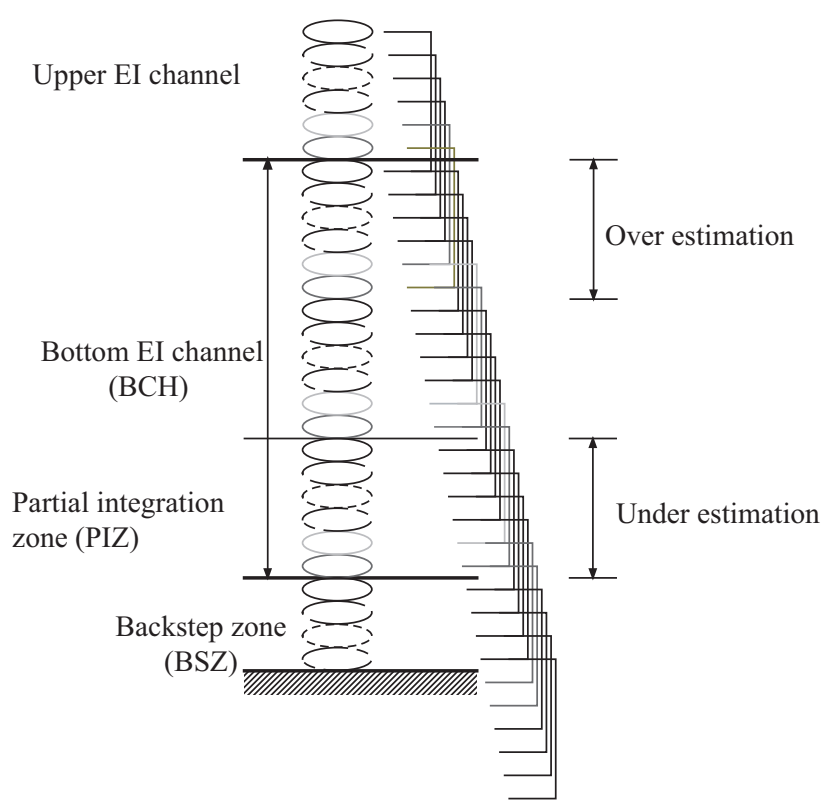

Fig. 12. Interpretation of the partial integration zone.

channel due to fish in the upper EI channel. Since the EI averages echo power for broad area, the condition of homoge neous and large distribution is satisfied in most cases. Also, the thickness of PIZ is $c \tau / 2$ and small. Therefore, the PIZ is not so significant.

\section{Dead Zones Induced by Steep Slope and Rough Seabed}

Still remain more fatal dead zones for a steeply sloped seabed and an extremely rough seabed. Lawson and Rose proposed a method to correct for underestimation in such case by using detectability [13]. Also, more instrumental countermeasures have already been proposed and realized. A sharp and stabilized beam [24] or a deep tow [12] was successfully used. Trenkel et al. compared bottom echoes by a traditional quantitative echo sounder (KR70, Simrad) using a $7^{\circ}$-beam and by a multi-beam 
echo sounder (E70, Simrad) using $2.2^{\circ}$-beam with a beam stabilization function and demonstrated that the stabilized sharp beam could minimize the dead zone. Our effort has lessened and will lessen restriction from the dead zones.

\section{Summary}

We summarize this section:

1) There is no "acoustic dead zone" and there appears unsampled zone, but the zone is very small and negligible;

2) The dead zone and the unsampled zone are different, and the latter can be estimated by neighboring data or can be sampled by another sounding strategy;

3) In principle, the echo of a fish touching with seabed can be measured, but actually some backstep is necessary to cause a dead zone;

4) The backstep zone can be compensated by using average SV of upper neighboring layer, but without careful scrutiny some error should be introduced;

5) Partial integration zone is not so significant, because the EI process makes distribution large and homogeneous and the upper EI channel compensates for lost energy; and

6) Extensive seabed slope and ruggedness cause dead zones, but they are resolved by using a special base like a deep tow or by using a sharp and stable beam.

\section{SEABED ECHO INTEGRATION}

The EI of seabed echoes is performed by setting an integration layer so as to include bottom echoes to get "bottom SV." The integration of seabed echoes is effective tool to check sailing loss [11], to make simple inter-ship calibration [11], to check overall performance of a quantitative echo sounder [1], and to measure surface scattering strength and estimate bottom material [14]. To demonstrate an application of the EI near the seabed, a method that measures simultaneously the bottom surface scattering strength (SS) and the SV of fish near the seabed is introduced [15]; the method gives quantitative information on fish and their habitat.

We developed a rather simple bottom scattering theory called equivalent surface scattering (ESS) theory. Scattering or reflection from the seabed is a complicated and multifold phenomenon [2]. It includes a specular reflection from a flat surface, surface scattering from a rough surface, and volume scattering from particles just below a surface. But, in the ESS theory, all the effects are representatively or equivalently combined as the SS.

Here the essence of the theory [14] is shown. As shown in Fig. 13, scattering surface starts form a point, grows as circles (left) and later as circular rings (right). The application of the same pre-processing (see Eq .(5)) for the bottom echo as the EI gives raw "volume backscattering strength" of the seabed, $S_{V B}$ :

$$
S_{V B}=\frac{\Phi}{\Psi} \frac{2}{c \tau} S_{S}
$$

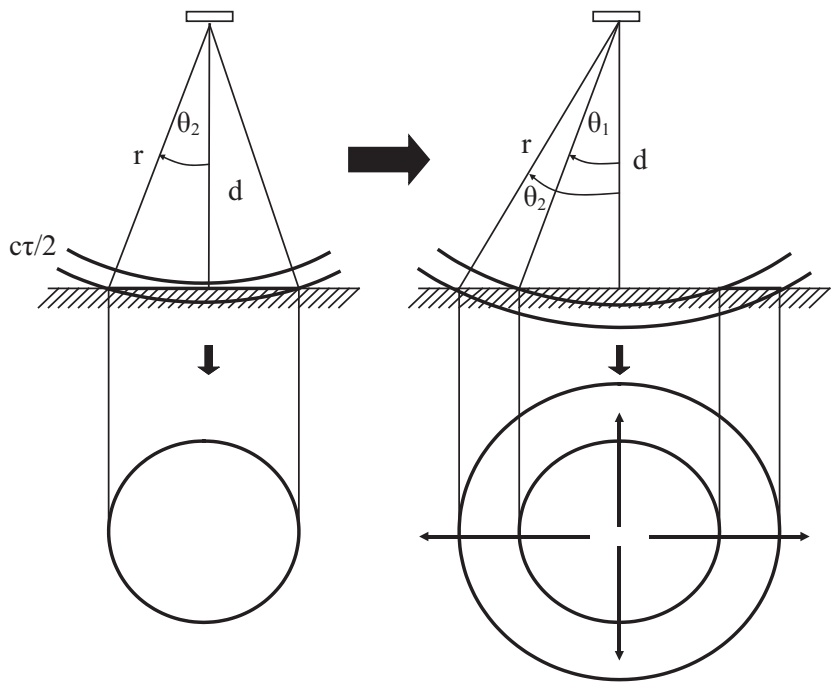

Fig. 13. Equivalent surface scattering model of the seabed. Scattering surface develops from circles (left) to circular rings (right) with time.

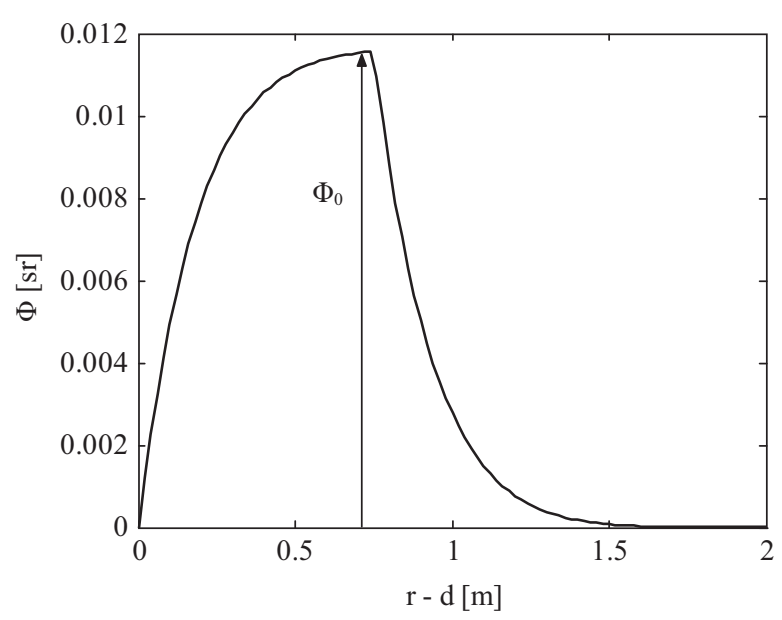

Fig. 14. Equivalent beam angle $\Phi$ of surface backscattering as a function of range minus depth $(r-d)$. The asymptotic value $\Phi_{0}$ is nearly equal to the equivalent beam angle $\Psi$ for volume back scattering strength.

$$
\Phi=\int_{0}^{2 \pi} \int_{\theta_{1}}^{\theta_{2}} D^{4} \theta d \theta d \phi
$$

where $S_{S}$ is the raw equivalent surface backscattering strength (raw SS) of seabed, $\Phi$ is the instantaneous equivalent beam angle for surface scattering, $\theta$ 's are angles indicated in Fig. 13, and $\Psi$ is the equivalent beam angle for volume backscattering defined by Eq. (6). $\Phi$ also represents bottom echo shape as shown in Fig. 14 and its asymptotic value, $\Phi_{0}$, becomes nearly equal to $\Psi$.

$$
\Psi \cong \Phi_{o}
$$

Therefore, from the measured $S_{V B}, S_{S}$ is obtained. 

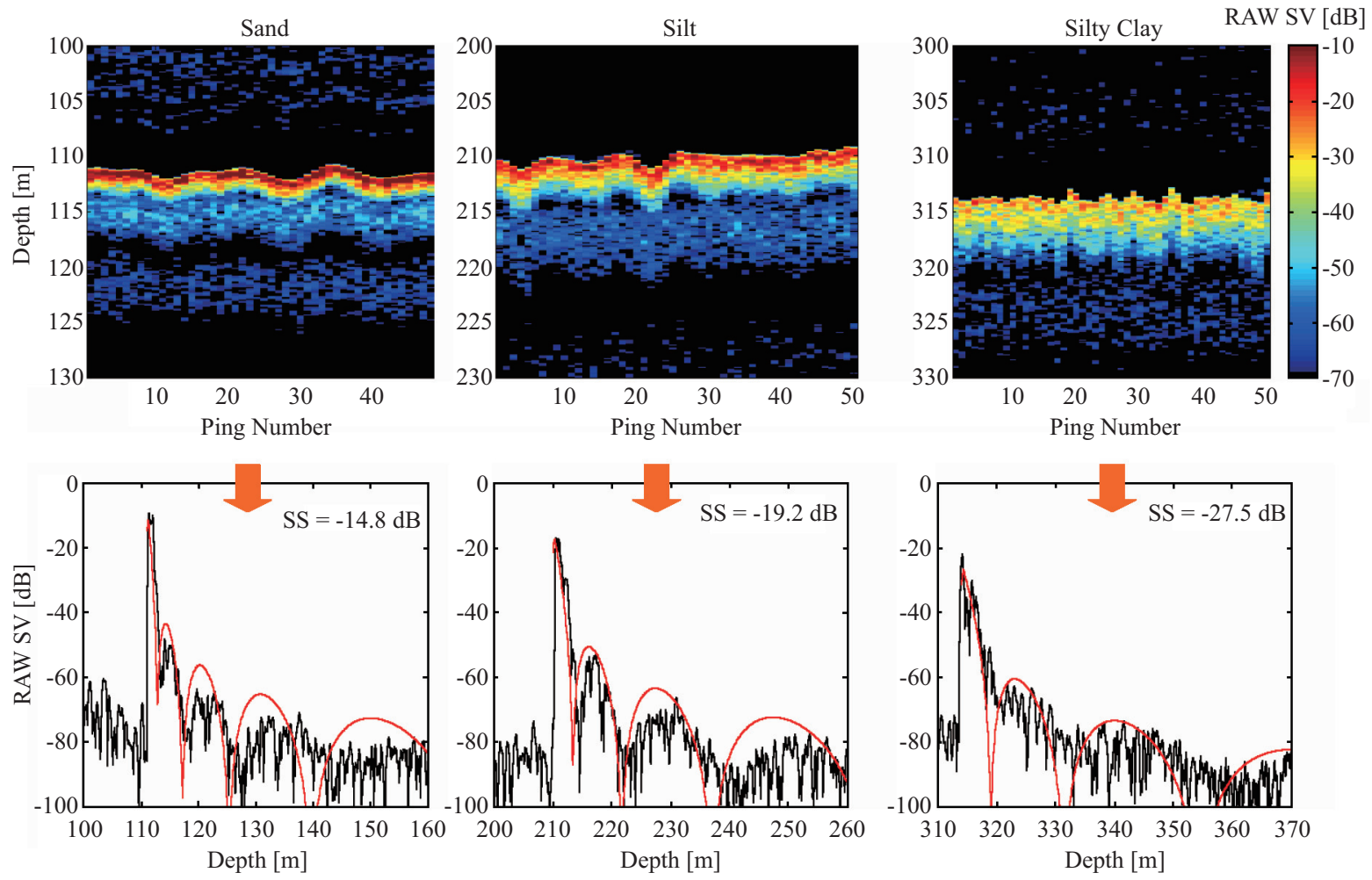

Fig. 15. Typical echograms of sea bottom (upper) and measured (lower, black) and modeled (lower, orange) echo envelopes in raw SV.

The EI of the raw SV yields an average equivalent surfacebackscattering-strength (average SS):

$$
<S_{S}>=r_{w}<S_{V B}>
$$

where $<\ldots>$ denotes averaging by EI and $r_{w}$ is the integration layer width including the bottom echoes. Therefore, the measurement of $\left\langle S_{V B}>\right.$ by the EI gives an estimate of $\left\langle S_{S}>\right.$ of the seabed. The basis of the several applications of the seabed EI cited in the beginning of this section is this fact; if the seabed is approximately flat and homogeneous, the seabed EI output can be used as a reference.

Examples of the application of the above method are demonstrated below. A survey was conducted by a quantitative echo sounder (KFC-3000, Sonic) onboard a research and training vessel "Umitaka-maru" of Tokyo University of Marine Science and Technology in the sea area off Java Island, Indonesia, in 2003. The sounder specifications are: frequency 38 , 70 , and $120 \mathrm{kHz}$, pulse width approximately $0.5 \mathrm{~ms}$, and beam width approximately $8.6^{\circ}$. Bottom materials were sampled by a dredge and analyzed afterward in a laboratory.

Fig. 15 compares raw SV of seabed by the experiment and the ESS theory. The materials were sand, silt, and silty clay and approximate depths of $100 \mathrm{~m}, 200 \mathrm{~m}$, and $300 \mathrm{~m}$ are different among the three, but the theory and observation coincide well. Fig. 16 plots the average SS against the particle diameter. The results show apparent relationship between the diameter

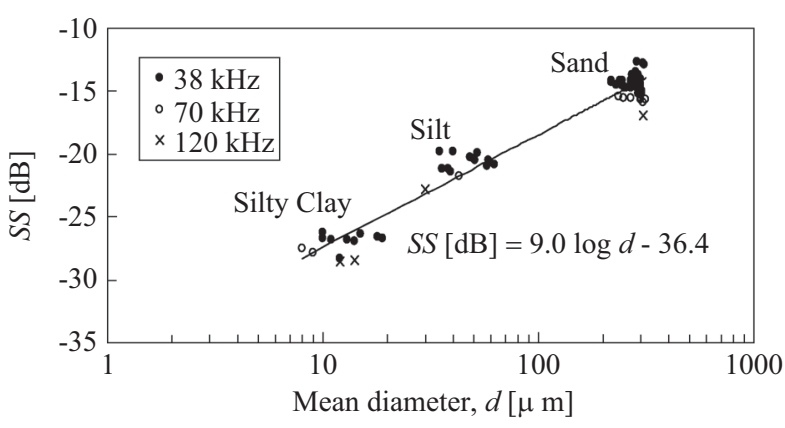

Fig. 16. Relationship between measured average SS for three frequencies and particle diameter, $d[\mu \mathrm{m}]$. The regression line is indicated.

and the average SS, suggesting that seabed types can be roughly estimated from the average SS.

A display of the raw SS of the seabed along with the raw SV of fish school just above the seabed like Fig. 17 is effective to observe fish distribution simultaneously with seabed type as their habitat. The echogram was obtained at $38 \mathrm{kHz}$; the seabed is fixed and $5 \mathrm{~m}$ above the seabed is expanded. The bottom depth was $110 \mathrm{~m}$, the raw SV is from -65 to $-55 \mathrm{~dB}$, and the average $\mathrm{SS}$ is $-8 \mathrm{~dB}$. From this SS value the bottom material is estimated to be sand. It is seen that the fish SV could be measured just above the seabed as discussed in the previous section. This technique will serve for demersal fish surveys and fisheries. 


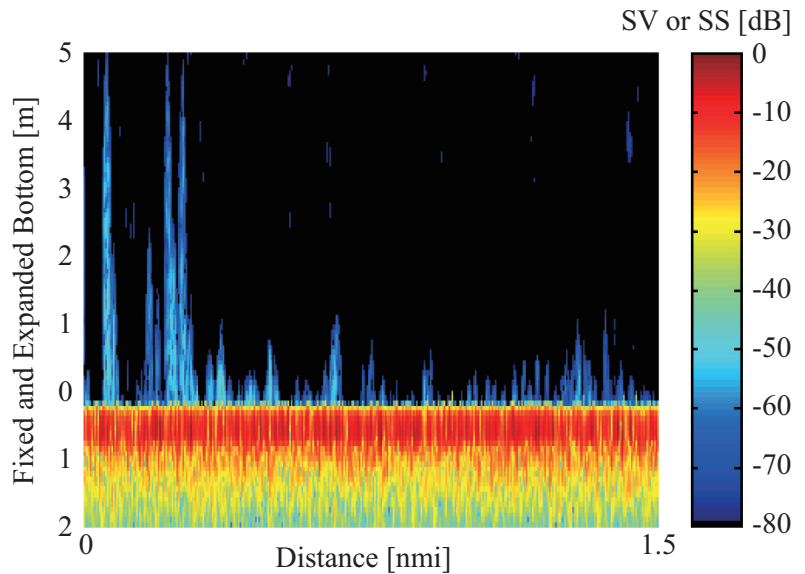

Fig. 17. Echogram showing raw SS of bottom and raw SV of fish school simultaneously.

Summaries of this section:

1) The equivalent surface scattering theory connected with the echo integration method gives equivalent surface scattering strength (SS);

2) The theory and method were validated by comparing with the experimental data;

3) The SS can be a good index for seabed materials; and

4) Echogram simultaneously displaying the raw SV of fish school and raw SS of seabed will be useful for demersal fish surveys.

\section{REFERENCES}

1. Aoyama, C., Hamada, E., and Furusawa, M., "Total performance check of quantitative echo sounders by using echoes from sea bottom," Nippon Suisan Gakkaishi, Vol. 65, pp. 78-85 (1999). (in Japanese)

2. Chotiros, N. P., "Reflection and reverberation in normal incidence echosounding," Journal of Acoustical Society of America, Vol. 96, pp. 29212929 (1994).

3. Diner, N., "Evaluating uncertainty in measurements of fish-shoal, aggregate-backscattering cross section caused by small shoal size relative to beam width," Aquatic Living Resources, Vol. 20, pp. 117-121 (2007).

4. Dragesund, O. and Olsen, S., "On the possibility of estimating year-class strength by measuring echo abundance of 0-group fish," Fiskeridirektoratets Skrifter Serie Havunderskelser, Vo. 13, pp. 48-75 (1965).

5. Eyring, C. F., Christensen, R. J., and W. Raitt, R., "Reverberation in the sea," Journal of Acoustical Society of America , Vol. 20, pp. 462-475 (1948).

6. Foote, K. G., "Linearity of fisheries acoustics, with addition theorems," Journal of Acoustical Society of America, Vol. 73, pp. 1932-1940 (1983).

7. Furusawa, M. and Amakasu, K., "Exact simulation of fish school echoes and its application," IEEE Oceans, Aprill 8-12, Kobe, Japan (2008).

8. Furusawa, M., Hamada, M., and Aoyama, C., "Near range error in sound scattering measurements of fish," Fisheries Science, Vol. 65, pp. 108-115
(1999).

9. Furusawa, M., Ishi, K., and Maniwa, Y., "A theoretical investigation on ultrasonic echo method to estimate distribution density of fish," Journal of Acoustical Society of Japan, Vol. 42, pp. 2-8 (1986). (in Japanese)

10. Furusawa, M., Ishii, K., Miyanohana, Y., and Maniwa, Y., "Experimental investigation of an acoustic method to estimate fish abundance using culture nets," Japan Journal of Applied Physics, Vol. 23(S1), pp. 101-103 (1984).

11. Furusawa, M. and Miyanohana, Y., "Intership calibration and sailing loss measurement by quantitative echo sounders," Technical Report of $\mathrm{Na}$ tional Research Institute of Fisheries Engineering (Fishing Boat and Instrument), Vol. 4, pp. 61-71 (1983). (in Japanese)

12. Kloser, R. J., "Improved precision of acoustic surveys of benthopelagic fish by means of a deep-towed transducer," ICES Journal of Marine Science, Vol. 53, pp. 407-413 (1996).

13. Lawson, G. L. and Rose, G. A., "The importance of detectability to acoustic surveys of semi-demersal fish," ICES Journal of Marine Science, Vo. 56, pp. 370-380 (1999).

14. Manik, H. M., Furusawa, M., and Amakasu, K., "Measurement of sea bottom surface backscattering strength by quantitative echo sounder," Fisheries Science, Vol. 72, pp. 503-512 (2006).

15. Manik, H. M., Furusawa, M., and Amakasu, K., "Quantifying sea bottom surface backscattering strength and identifying bottom fish habitat by quantitative echo sounder," Japanese Journal of Applied Physics, 45, pp. 4865-4867 (2006).

16. Mitson, R. B., "Acoustic detection and estimation of fish near the sea-bed and surface," FAO Fisheries Report, No. 300, pp. 27-34 (1983).

17. Moose, P. H. and Ehrenberg, J. E., "An expression for the variance of abundance estimates using a fish echo integrator," Journal Fisheries Research Board of Canada, Vol. 28, pp. 1293-1301 (1971).

18. Ona, E. and Mitson, R. B., "Acoustic sampling and signal processing near the seabed: the deadzone revisited," ICES Journal of Marine Science, Vol. 53, pp. 677-690 (1996).

19. Patel, R., Pedersen, G., and Ona, E., "Inferring the acoustic dead-zone volume by split-beam echo sounder with narrow-beam transducer on a noninertial platform," Journal of Acoustical Society of America, Vol. 125, pp. 698-705 (2009).

20. Saneyoshi, J., Kikuchi, Y., and Nomoto, O., Chouonpa Gijyutu Binran (Handbook of ultrasonic technology), Nikkan Kogyo Shinbun Sha, Tokyo (1960). (in Japanese)

21. Saneyoshi, J. and Nakamura, K., "Theory and model experiment on reflection of ultrasonic waves from numerous reflectors," Journal of Acoustical Society of Japan, Vol. 8, pp. 123-127 (1952). (in Japanese)

22. Simmonds, J. and MacLennan, D., Fisheries Acoustics: Theory and Practice, 2nd ed., Blackwell, Oxford (2005).

23. Thorne, R. E., "Investigation into the relation between integrated echo voltage and fish density," Journal Fisheries Research Board of Canada, Vol. 28, pp. 1269-1273 (1971).

24. Trenkel, V. M., Mazauric, V., and Berger, L., "The new fisheries multibeam echosounder ME70: description and expected contribution to fisheries research," ICES Journal of Marine Science, Vol. 65, pp. 645-655 (2008).

25. Truskanov, M. D. and Scherbino, M. N., "Methods of direct calculation of fish concentrations by means of hydroacoustic apparatus," Paper presented to the Seminar on Fishery Biology and Oceanography, Moscow, pp. 1-22 (1964).

26. Urick, R. J., Principle of underwater sound, Peninsula Publishing, California (1983). 